\title{
Freshening of the Labrador Sea as a trigger for Little Ice Age development
}

\author{
Montserrat Alonso-Garcia ${ }^{1,2,3}$, Helga (Kikki) F. Kleiven ${ }^{4}$, Jerry F. McManus ${ }^{5}$, Paola Moffa-Sanchez ${ }^{6}$, \\ Wallace S. Broecker ${ }^{5}$, and Benjamin P. Flower ${ }^{1, \dagger}$ \\ ${ }^{1}$ College of Marine Science, University of South Florida, St. Petersburg, FL, USA \\ ${ }^{2}$ Instituto Português do Mar e da Atmosfera (IPMA), Div. de Geologia e Georecursos Marinhos, Lisbon, Portugal \\ ${ }^{3}$ Centro de Ciencias do Mar (CCMAR), Universidade do Algarve, Faro, Portugal \\ ${ }^{4}$ University of Bergen and Bjerknes Centre for Climate Research, Postboks 7803, 5020 Bergen, Norway \\ ${ }^{5}$ Department of Earth and Environmental Sciences, Lamont-Doherty Earth Observatory of Columbia University, \\ Palisades, NY 10964-8000, USA \\ ${ }^{6}$ School of Earth and Ocean Sciences, Cardiff University, Park Place, CF10 3 YE, Cardiff, UK \\ $\dagger$ deceased
}

Correspondence to: Montserrat Alonso-Garcia (montserrat.alonso@ipma.pt)

Received: 10 July 2016 - Discussion started: 2 August 2016

Revised: 20 January 2017 - Accepted: 3 March 2017 - Published: 7 April 2017

\begin{abstract}
Arctic freshwater discharges to the Labrador Sea from melting glaciers and sea ice can have a large impact on ocean circulation dynamics in the North Atlantic, modifying climate and deep water formation in this region. In this study, we present for the first time a high resolution record of ice rafting in the Labrador Sea over the last millennium to assess the effects of freshwater discharges in this region on ocean circulation and climate. The occurrence of ice-rafted debris (IRD) in the Labrador Sea was studied using sediments from Site GS06-144-03 (57.29 ${ }^{\circ} \mathrm{N}, 48.37^{\circ} \mathrm{W}$; $3432 \mathrm{~m}$ water depth). IRD from the fraction $63-150 \mu \mathrm{m}$ shows particularly high concentrations during the intervals AD 1000-1100, $\sim 1150-1250, \sim 1400-1450, \sim 1650-1700$ and $\sim 1750$ 1800. The first two intervals occurred during the Medieval Climate Anomaly (MCA), whereas the others took place within the Little Ice Age (LIA). Mineralogical identification indicates that the main IRD source during the MCA was SE Greenland. In contrast, the concentration and relative abundance of hematite-stained grains reflects an increase in the contribution of Arctic ice during the LIA.

The comparison of our Labrador Sea IRD records with other climate proxies from the subpolar North Atlantic allowed us to propose a sequence of processes that led to the cooling that occurred during the LIA, particularly in the Northern Hemisphere. This study reveals that the warm cli-
\end{abstract}

mate of the MCA may have enhanced iceberg calving along the SE Greenland coast and, as a result, freshened the subpolar gyre (SPG). Consequently, SPG circulation switched to a weaker mode and reduced convection in the Labrador Sea, decreasing its contribution to the North Atlantic deep water formation and, thus, reducing the amount of heat transported to high latitudes. This situation of weak SPG circulation may have made the North Atlantic climate more unstable, inducing a state in which external forcings (e.g. reduced solar irradiance and volcanic eruptions) could easily drive periods of severe cold conditions in Europe and the North Atlantic like the LIA. This analysis indicates that a freshening of the SPG may play a crucial role in the development of cold events during the Holocene, which may be of key importance for predictions about future climate.

\section{Introduction}

The last millennium is an important target in palaeoclimate studies since this interval allows us to reconstruct the climate variability of our recent history and its impact on the development of our society. Moreover, climate reconstructions of the last millennium combined with instrumental records constitute a framework to obtain a comprehensive understand- 
ing of the mechanisms that drive the Earth's climate and improve future climate predictions. The climate of the last millennium is characterized by a warm period called the Medieval Climate Anomaly (MCA) or Medieval Warm Period ( AD 800-1200), a cold interval called the Little Ice Age (LIA, AD 1350-1850) and the 20th century warming trend (e.g. Mann et al., 2009; Wanner et al., 2011). According to historical records, these climate oscillations affected human development in Europe, in particular the Norse expansion and demise in the North Atlantic (Ogilvie et al., 2000). The warm conditions of the MCA promoted the colonization of Iceland and Greenland by the Norse and the exploration of North America during the 9th to 12th centuries, whereas their maladaptation to climate deterioration at the beginning of the LIA led them to abandon the Greenland settlements by the end of the 15th century (Dugmore et al., 2012; Kuijpers et al., 2014; Ogilvie et al., 2000).

Reconstructions of ocean and land temperature show the LIA cooling was neither spatially nor temporally uniform (Bradley et al., 2003; PAGES 2k Consortium, 2013; Wanner et al., 2011, 2015), and therefore there is an open debate on the forcings that may have triggered these climate oscillations. Reduced solar irradiance and the occurrence of explosive volcanic eruptions are the two most commonly examined forcings (e.g. Bond et al., 2001; Miller et al., 2012) due to the impact they may have on atmospheric dynamics. Other forcings such as the internal dynamics of the oceanic and atmospheric systems (such as the North Atlantic Oscillation, NAO; Arctic Oscillation, AO; Atlantic Multidecadal Oscillation, AMO; El Niño-Southern Oscillation, ENSO; or the monsoonal regimes) have also been considered to play a major role driving climate oscillations during the last century (see review in Wanner et al., 2011). Freshwater discharge to the North Atlantic may also be a driver of climate change by impacting sea surface circulation and deep water convection, which in turn may slow down the Atlantic Meridional Overturning Circulation (AMOC) (Manabe and Stouffer, 1995). The Labrador Sea is particularly sensitive to increases in freshwater and sea ice input. Deep water formation in the Labrador Sea contributes $30 \%$ of the volume transport of the deep limb of the AMOC (Rhein et al., 2002; Talley, 2003), and freshwater input to this region can potentially reduce oceanic deep convection, slowing down the Atlantic circulation and its related oceanic heat transport (Born et al., 2010; Moreno-Chamarro et al., 2015). The decrease in heat export from low to high latitudes modifies regional climate by cooling the western North Atlantic, which, in turn, influences the climate of the whole North Atlantic (Born et al., 2010). A recent example of this phenomenon may be the "Great Salinity Anomaly" event that occurred between 1968 and 1982 (Dickson et al., 1988). During this interval, vast amounts of Arctic sea ice and freshwater were delivered to the Labrador Sea, mainly via the East Greenland Current (EGC), freshening the subpolar gyre (SPG) and decreasing winter convection and deep water production. A recent study of the last
50 years also shows a close relationship between freshwater fluxes from the Arctic and reductions in deep water formation in the Labrador Sea (Yang et al., 2016).

Recently, attention has been given to the dynamics of the SPG and its relationship with climate (e.g. Born and Stocker, 2014). Instrumental records and modern observations show a close link between decadal climate variability and SPG dynamics (e.g. Hakkinen and Rhines, 2004; Sarafanov, 2009), and rapid climate change reconstructions of the Holocene and the last interglacial period have been interpreted as a consequence of changes in the SPG dynamics (Moffa-Sanchez et al., 2014a; Mokeddem and McManus, 2016; Mokeddem et al., 2014; Moros et al., 2012; Thornalley et al., 2009). Variations in the strength and shape of the SPG also impact deep convection in the Labrador Sea, therefore influencing deep water production and Atlantic circulation (Böning et al., 2006; Hatun et al., 2005; Moreno-Chamarro et al., 2015), which eventually affects climate through the reduction of heat transported from low to high latitudes. A shift to weak SPG circulation has been inferred using deep-sea corals after AD 1250 (Copard et al., 2012), and model simulations suggested this weakening of the SPG was the main driver of the LIA due to the decrease in meridional heat transport to the subpolar North Atlantic (Moreno-Chamarro et al., 2017). Moreover, the occurrence of unusually cold winters in Europe during the last 100 years has been associated with atmospheric blocking events in the North Atlantic, which are high-pressure systems that alter the normal westerly wind circulation in this region (Häkkinen et al., 2011). These events are associated with negative AO, may modify surface circulation in the North Atlantic, and are linked to cold winter temperature in western Europe (Shabbar et al., 2001). Periods of intense and persistent atmospheric blocking events very likely developed during the LIA due to the influence of low solar irradiance and weak SPG circulation, causing decadal intervals of severe cooling in Europe (Moffa-Sanchez et al., 2014a).

In this work we used a sediment core from the Eirik Drift, in the Labrador Sea, to reconstruct ice-rafting occurrence during the last 1200 years and examine its impact on SPG dynamics and climate. The presence of ice-rafted debris (IRD) is a proxy for iceberg and sea ice discharges. Our IRD record from the Eirik Drift indicates ice export to the Labrador Sea and allows us to infer periods of enhanced freshwater discharges. Previous Holocene multi-proxy records (including IRD records) from the North Atlantic pointed to the linkage between cooling events and low solar irradiance values (Bond et al., 2001). However, this hypothesis has been challenged by the observation that ice-rafting reconstructions in the northern North Atlantic show different trends between the eastern and western regions during the Holocene (Moros et al., 2006). The combination of our IRD data with other records from Eirik Drift as well as other subpolar North Atlantic sites allows us to present a comprehensive reconstruction of the transition from the MCA to the LIA. This study 


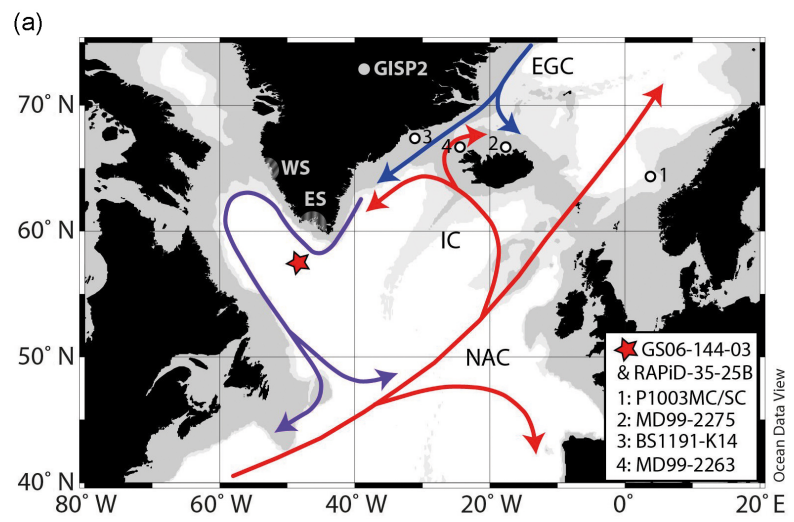

(b)

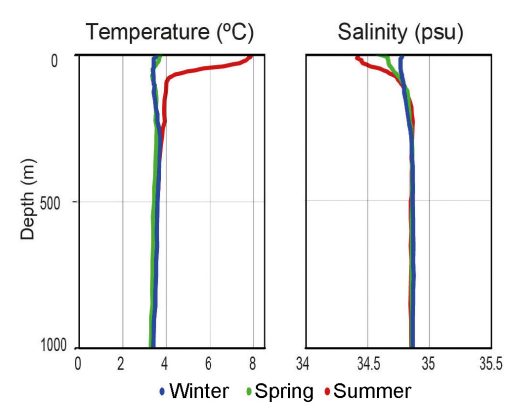

Figure 1. (a) Location of multicore GS06-144-03 (red star) and other sites in the northern North Atlantic whose records have been used to support the discussion proposed in this work. General North Atlantic circulation is shown according to Schmitz and McCartney (1993). The location of Norse settlements in Greenland is shaded and indicated with ES (eastern settlement) and WS (western settlement). (b) Temperature and salinity profiles of the first $1000 \mathrm{~m}$ at site GS06-144-03 obtained through Ocean Data View (https://odv.awi.de/) from the World Ocean Atlas 2013 (Locarnini et al., 2013; Zweng et al., 2013).

reveals the importance of ice discharges in modifying surface circulation in the SPG, as a driver of oscillations in climatic patterns and deep water production in the past, and perhaps again in the future.

\section{Geological and oceanographic setting}

Site GS06-144-03 (57.29 N, 48.37 ${ }^{\circ} \mathrm{W} ; 3432 \mathrm{~m}$ water depth) is located in the southern tip of Greenland at the Eirik drift (Fig. 1). The site is placed in the northwest part of the SPG, a very sensitive area to climatic and oceanographic changes given that the upper North Atlantic deep water forms in this region (Schmitz and McCartney, 1993). The SPG boundary currents are formed by the North Atlantic Current (NAC); the Irminger Current, which is the western branch of the NAC and flows towards Greenland; the East Greenland Current (EGC); and the Labrador Current (Fig. 1). The Irminger Current brings warm and high-salinity water to the Labrador Sea, whereas the EGC and Labrador Current transport colder and lower salinity water and frequently carry icebergs and sea ice from the Arctic area.

Oscillations in the amount of ice transported by the EGC and Labrador Current may result in freshening of the SPG affecting the strength of SPG circulation. Fluctuations in the SPG circulation have been suggested as the driver of oscillations in decadal deep water production and climate variability in the North Atlantic and surrounding continents (Böning et al., 2006; Hakkinen and Rhines, 2004; Hatun et al., 2005). Two states of equilibrium have been described depending on the strength of the SPG circulation: (1) when the circulation is strong, more salty water is advected to the centre of the gyre, favouring deep water formation in this area, whereas (2) when the circulation is weak more salty water is advected northeastward to the Nordic Seas and the SPG water gets fresher, which prevents deep convection in the Labrador Sea
(Born and Stocker, 2014). However, some increased convection may occur in the Irminger Basin and Nordic Seas, counterbalancing the lack of Labrador Sea convection. Changes in the dynamics of the SPG are mainly driven by cyclonic winds and buoyancy forcing (Born and Stocker, 2014); therefore, freshwater input via iceberg discharges may be a critical factor modifying the circulation in the SPG and deep water formation in the Labrador Sea.

\section{Materials and methods}

Sediments from core GS06-144-03 MC-A were drilled using a multicore device during a cruise on the R/V G.O. Sars (Dokken and Ninnemann, 2006). A robust chronology has been developed based on 12 accelerator mass spectrometry (AMS) ${ }^{14} \mathrm{C}$ dates performed on the calcareous shells of the planktonic foraminifer Neogloboquadrina pachyderma sinistral and ${ }^{210} \mathrm{~Pb}$ measurements at the top of the core. The dates were analysed on the accelerator mass spectrometer at the Leibniz Labor für Altersbestimmung und Isotopenforschung in Kiel, Germany. Radiocarbon ages have been converted into calendar years using the CALIB (rev 5.0.1) software (Stuiver and Reimer, 1993) in conjunction with the Marine04 calibration dataset (Hughen et al., 2004). All dates were calibrated with a constant surface reservoir age of 400 years. The sample at $0 \mathrm{~cm}$ showed erroneous age because of severe addition of more than $100 \%$ modern carbon (pMC) and is assumed to be post-AD 1962 (relative to the increase in bomb radiocarbon levels in the North Atlantic region). The core was collected in 2006 and the cesium spike and ${ }^{210} \mathrm{~Pb}$ measurements in the upper $12 \mathrm{~cm}$ of the core sediments confirms post-AD 1964 age. Table 1 shows the uncorrected ${ }^{14} \mathrm{C}$ ages and calibrated ages.

Sediment samples were taken continuously every $0.5 \mathrm{~cm}$ $(0-41.5 \mathrm{~cm})$, and the high sedimentation rate at this site al- 
Table 1. Site GS06-144-03 MC-A chronology, based on 12 accelerator mass spectrometry (AMS) ${ }^{14} \mathrm{C}$ dates performed on the calcareous shells of the planktonic foraminifera Neogloboquadrina pachyderma sinistral.

\begin{tabular}{|c|c|c|c|c|c|c|}
\hline Lab code ${ }^{a}$ & $\begin{array}{l}\text { Core depth } \\
(\mathrm{cm})\end{array}$ & Species $^{b}$ & $\begin{array}{l}\text { Uncorrected } \\
{ }^{14} \mathrm{C} \text { age } \\
\text { (years) } \pm 1 \sigma \\
\text { error }\end{array}$ & $\begin{array}{l}\text { Calibrated } \\
\text { age }(\mathrm{AD})^{\mathrm{c}} \\
(\text { median } \\
\text { probability) }\end{array}$ & $1 \sigma$ age range & Remarks \\
\hline KIA34239 & 0 & Nps & $145 \pm 20 \mathrm{BP}^{*}$ & 1984 & 2006-1962 & Bomb ${ }^{14} \mathrm{C}$ \\
\hline KIA41679 & 2 & Nps & $555 \pm 30 \mathrm{BP}$ & 1739 & $1701-1776$ & \\
\hline KIA43514 & 4.5 & $\mathrm{Nps}$ & $640 \pm 25 \mathrm{BP}$ & 1669 & $1647-1690$ & \\
\hline KIA43515 & 5.5 & Nps & $740 \pm 25 \mathrm{BP}$ & 1563 & $1526-1600$ & \\
\hline KIA41681 & 8 & Nps & $760 \pm 25 \mathrm{BP}$ & 1540 & $1497-1582$ & \\
\hline KIA36383 & 10 & Nps & $815 \pm 25 \mathrm{BP}$ & 1490 & $1466-1514$ & \\
\hline KIA36384 & 12 & Nps & $890 \pm 25 \mathrm{BP}$ & 1447 & $1428-1465$ & \\
\hline KIA36385 & 18 & Nps & $1140 \pm 25 \mathrm{BP}$ & 1266 & $1241-1291$ & \\
\hline KIA36386 & 22 & Nps & $1225 \pm 35 \mathrm{BP}$ & 1192 & $1145-1238$ & \\
\hline KIA36387 & 28 & Nps & $1460 \pm 25 \mathrm{BP}$ & 948 & $910-986$ & \\
\hline KIA41682 & 32 & Nps & $1440 \pm 30 \mathrm{BP}$ & 968 & 926-1009 & \\
\hline KIA34241 & 36 & Nps & $1600 \pm 25 \mathrm{BP}$ & 777 & $734-819$ & \\
\hline
\end{tabular}

${ }^{\text {a }}$ KIA - Leibniz Labor für Altersbestimmung und Isotopenforschung, Kiel, Germany.

b Nps - Neogloboquadrina pachyderma sinistral.

${ }^{\text {c }}{ }^{14} \mathrm{C}$ ages were converted into calendar ages with the CALIB Rev 6.1.0 software and the MARINE09 calibration dataset, applying a standard 400a reservoir age correction.

* Sample marked with an asterisk had levels of more than $100 \%$ modern carbon (pMC) and is assumed to be post-AD 1962 (relative to the increase in bomb radiocarbon levels in the North Atlantic region). Core was collected in 2006.

lows us to reconstruct the ice-rafting history of the past 1200 years at a decadal-scale resolution (mean sedimentation rate of $0.029 \mathrm{~cm} \mathrm{yr}^{-1}$, on average $\sim 17$ years between samples). Samples were soaked in distilled water and shaken for $12 \mathrm{~h}$ in order to disperse the sediment. Then they were wetsieved and separated into size fractions of $>150,63-150$ and $<63 \mu \mathrm{m}$ and subsequently dried in an oven.

In order to study the IRD content we use the $63-150 \mu \mathrm{m}$ fraction. This size fraction is coarse enough to be delivered to the open ocean primarily by drifting ice rather than wind or currents (Fillon et al., 1981; Ruddiman, 1977), yet lends itself to detailed petrographic analysis (Bond and Lotti, 1995). Bond's technique (Bond et al., 1997) was robustly tested using several multicores in the polar-subpolar region and it was compared to counts in the $>150 \mu \mathrm{m}$ fraction. We acknowledge that grains $>250 \mu \mathrm{m}$ are the best fraction to claim transport by icebergs and sea ice because wind and deep currents can be confidently ruled out (Andrews, 2000). Unfortunately, the samples of our study interval do not contain enough grains in this fraction to develop a sound analysis to show trends in coarser IRD. We will need larger amounts of bulk sediment to perform significant counts of IRD $>250 \mu \mathrm{m}$. Even though it has been suggested that within the $63-150 \mu \mathrm{m}$ fraction some grains might be transported by other means (see discussion in Andrews et al., 2014), given the location of the study site (in the outer part of Eirik Drift) we think meltwater plumes are very unlikely and deep currents hardly transport sediments $>63 \mu \mathrm{m}$. Therefore, we can assume the
$63-150 \mu \mathrm{m}$ fraction we studied is mainly composed of IRD grains.

Each sample was split with a microsplitter to obtain an aliquot with about 200 IRD grains. The aliquots were placed in a transparent gridded tray and counted using a highmagnification stereomicroscope which incorporates a light source from the bottom, similar to the transmitted light, and a light source from the top which emulates reflected light. Using aliquots in a transparent tray instead of smear slides offers the possibility of moving the grains independently, thus allowing for a better identification. Additionally, the use of a transparent tray is a key factor to improve the identification of quartz and feldspar hematite-stained grains (HSGs) by the introduction of a white paper below the tray which enhances the contrast between the hematite-stained portion and the rest of the grain. This technique is similar to that described in Bond et al. (1997); however, the use of aliquots presents the advantage that IRD concentrations in the bulk sediment can be calculated to obtain the total number of IRD (and IRD types) per gram of bulk sediment. A minimum of 200 grains were counted in each sample and the calculated errors for the replicated samples are below $3.2 \%$. The identification of different groups of minerals such as HSGs of quartz and feldspar, unstained quartz and feldspar, and brown and white volcanic glass (VG) allows us to calculate the relative abundance of each type of IRD, which may be useful to identify the sources of the drifting ice that transported the IRD (e.g. Alonso-Garcia et al., 2013; Bailey et al., 2012). SEM X-ray diffraction was performed on selected grains with an energy 
dispersive spectroscopy (EDS) equipment at the facilities of the College of Marine Science (University of South Florida). The EDS equipment used is an EDAX X-ray microanalysis system with an Apollo 10 silicon drift detector.

Stable isotope analyses $\left(\delta^{18} \mathrm{O}\right)$ were performed on planktonic foraminifer shells of $N$. pachyderma sin to reconstruct near-surface water properties. Samples for isotopes were also taken every $0.5 \mathrm{~cm}$. N. pachyderma sin was picked from the $150-250 \mu \mathrm{m}$ size fraction. Before performing the analyses, the foraminiferal shells were ultrasonically rinsed for $20 \mathrm{~s}$ in methanol to remove fine-grained particles. Stable isotope ratios were obtained at the stable isotope laboratory at Department of Earth Sciences and the Bjerknes Centre for Climate Research at the University of Bergen, using Nier-type (gas source) mass spectrometers. The $\delta^{18} \mathrm{O}$ analyses of samples from $0-15.5 \mathrm{~cm}$ in the core were carried out on a Finnigan MAT251 mass spectrometer, while the rest of the samples $(15.5-41.5 \mathrm{~cm})$ were analysed on a MAT253 mass spectrometer. All planktonic samples were run in four replicates. The stable isotope results are expressed as the average of the replicates and reported relative to Vienna Pee Dee Belemnite (VPDB), calibrated using NBS-19. Long-term analytical precision $(1 \sigma)$ of the standards over a time interval of several months is $0.1 \%$ or the MAT253 system and $<0.08 \%$ for the MAT251 system.

\section{Results}

The total concentration of IRD (Fig. 2d) ranges from $\sim 9000$ to 116000 grains per gram of sediment (grains $\mathrm{g}^{-1}$ ), which means that icebergs and sea ice reached the studied area during the entire interval examined in this work. The highest peak of IRD concentration was reached at the end of the MCA (AD 1169) and the intervals with highest IRD concentration occurred approximately at AD 1000-1100, 1150$1250,1400-1450,1650-1700$ and $1750-1800$, with mean values above 50000 grains $\mathrm{g}^{-1}$. The first two of these five intervals of high ice rafting occurred during the MCA, whereas the other three intervals of high IRD concentration took place during the LIA.

Volcanic glass (VG) is one of the main components of IRD, with relative abundances up to $59 \%$ (Fig. 2c). This group includes brown VG fragments, usually not vesicular, and white VG fragments, which are very light and often with vesicular aspect. The concentration of the total VG shows a similar pattern to the total IRD concentration with the highest values during the same intervals (Fig. 2). The relative abundance of VG shows high values during the intervals of high total IRD concentration. The relative abundance of white VG is generally lower than $20 \%$ and does not show clear periods of high abundance that can be correlated with the records of volcanic eruptions (Gao et al., 2008; Sigl et al., 2015).

HSG relative abundance ranges between 2 and $30 \%$, reaching higher values than those observed at MC52 in the

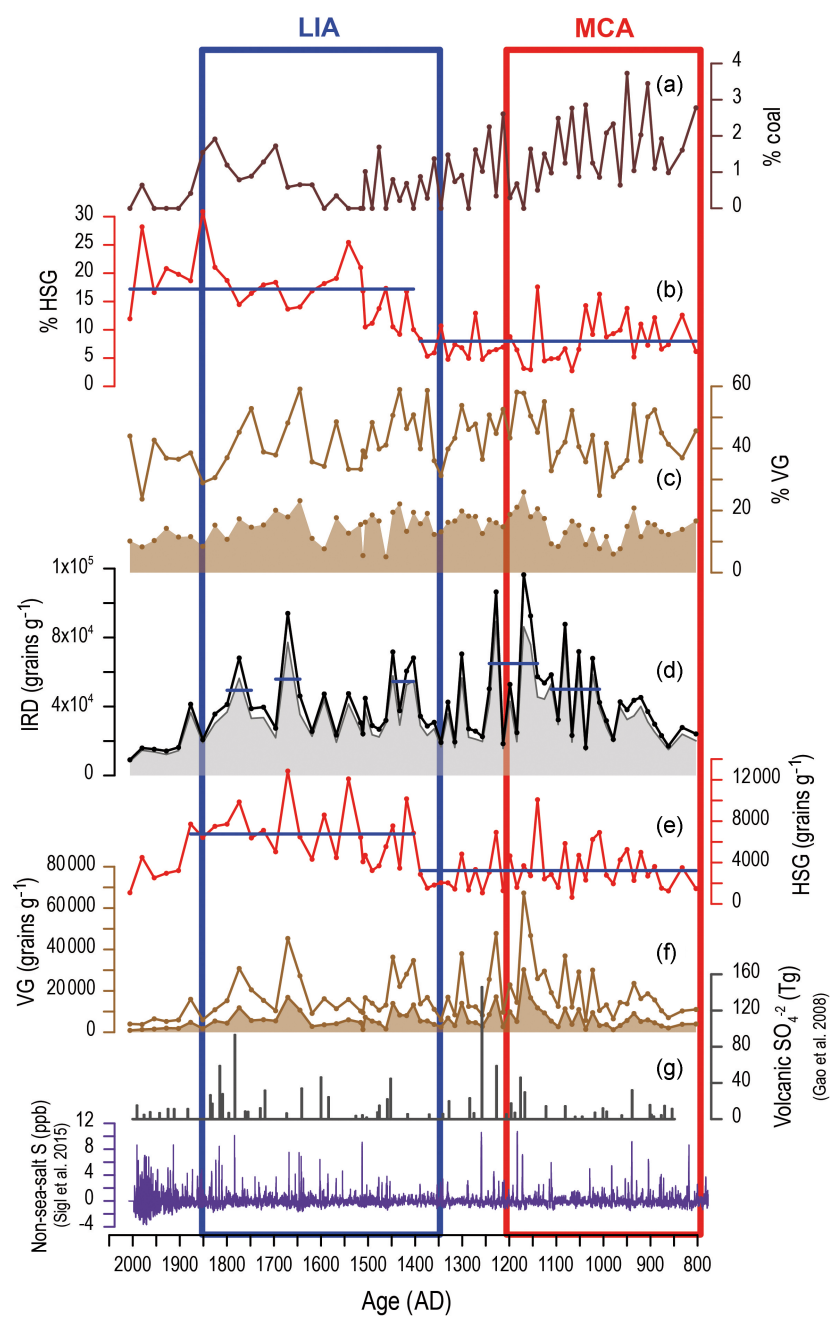

Figure 2. Ice-rafted debris (IRD) records from site GS06-14403. (a) Coal grains relative abundance; (b) hematite-stained grains (HSGs) relative abundance; (c) total volcanic glass (VG) relative abundance (brown line) and white VG relative abundance (shaded area); (d) total IRD concentration in each sediment sample (black line), and IRD concentration not including the white volcanic glass (shaded area); (e) concentration of HSGs; (f) concentration of total VG (brown line) and white VG (shaded area); and (g) Northern Hemisphere sulphate aerosol injection by volcanic eruptions (after Gao et al., 2008, revised in 2012) and non-sea-salt sulfur from the NEEM Greenland ice core (Sigl et al., 2015). Blue horizontal lines indicate mean values for the intervals they encompass. The approximate standard duration of the Little Ice Age (LIA) and Medieval Warm Period (MWP) has been depicted in blue and red squares respectively.

eastern North Atlantic (Fig. 3b, Bond et al., 2001). The record of HSG concentration shows a different pattern from the total IRD and VG records, with higher concentration from AD 1400 to 1900 (Fig. 2e). The relative abundance of HSGs is also higher after AD 1400, with mean values increasing to over $15 \%$ from near $5 \%$ before AD 1400 . This 


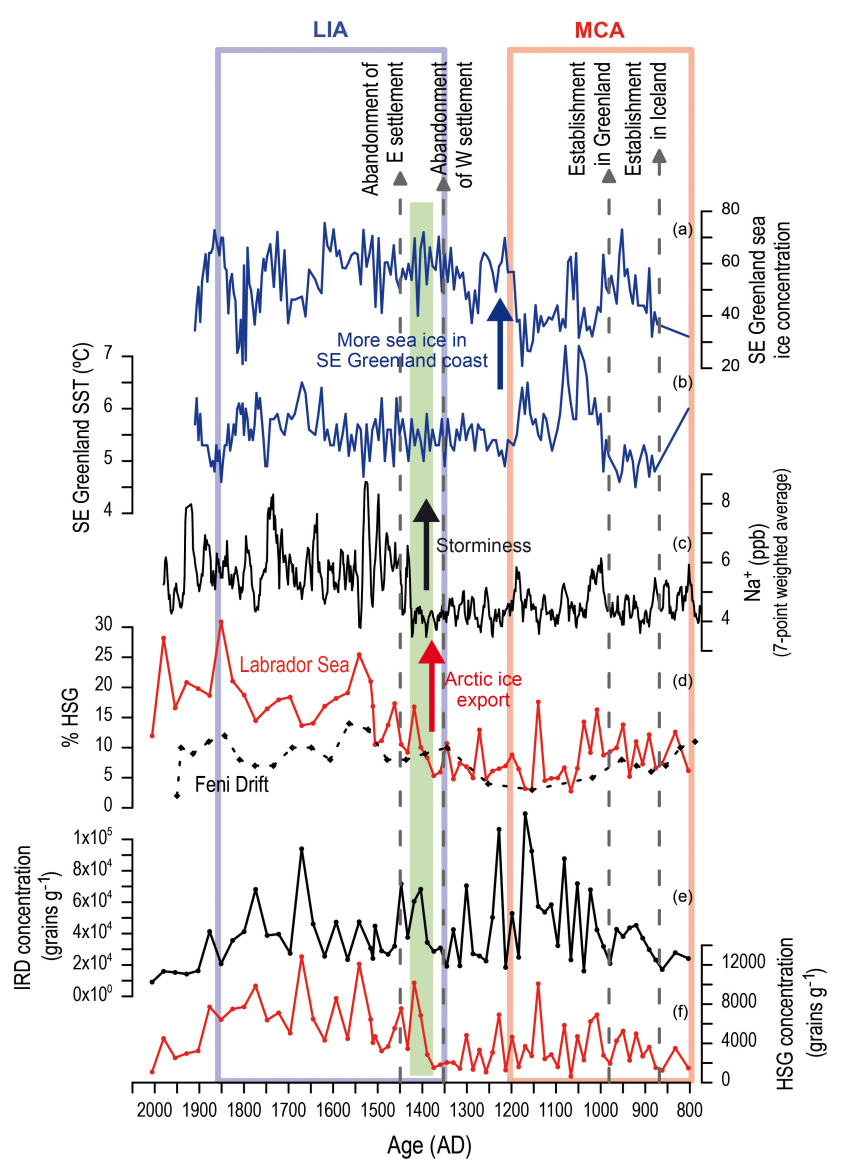

Figure 3. LIA shift at $\sim \mathrm{AD} 1400$ (green vertical bar) in several records compared to site GS06-144-03 IRD records. (a) SE Greenland April sea ice concentration (Miettinen et al., 2015); (b) SE Greenland April sea surface temperature (Miettinen et al., 2015); (c) $\mathrm{Na}^{+}$record from GISP2 (Meeker and Mayewski, 2002); (d) HSG record from Eirik Drift (red line) and from Feni Drift in the NE Atlantic (black dashed line; Bond et al., 2001); (e) total IRD concentration; and (f) HSG concentration. The main events in Norse colonization and abandonment of settlements are depicted at the top of the figure, according to Ogilvie et al. (2000).

range of variability is comparable to previous observations across the Atlantic in the late Holocene (Bond et al., 1997; 2001).

Among the selected grains to perform X-ray analysis we separated a group of black unclassified minerals. According to the SEM X-ray diffraction analysis, those grains are mainly composed of carbon, and we interpreted them as coal fragments. Those minerals occurred in higher abundance during the MCA and the end of the LIA.

\section{Discussion}

\subsection{IRD sources and significance}

The mineralogy found at Site GS06-144-03 suggests several lithological sources for the IRD which may be associated with icebergs or sea ice originated from different areas. Volcanic rocks mainly outcrop surrounding Denmark Strait, in Iceland and the Geikie Plateau area on the East Greenland coast (Bailey et al., 2012; Henriksen et al., 2009). Volcanic glass can also be atmospherically transported after volcanic eruptions and be ultimately incorporated in the ice as it has been shown in Greenland ice core records (Grönvold et al., 1995). This is very likely the case of the white VG fragments found in our record because our counts of white VG (Fig. 2) do not suggest the presence of any discrete layer that could be associated with any dated Icelandic eruption (Gao et al., 2008; Sigl et al., 2015). This type of IRD was probably deposited on the top of glaciers and sea ice near Iceland and the East Greenland coast and then transported in the ice through the EGC. Although some of those volcanic shards ejected to the atmosphere could have fallen directly in the sea, the preferentially eastward dispersal pattern of Icelandic tephra follows the predominantly westerly winds in the stratosphere (Lacasse, 2001) and, hence, the amount of volcanic glass transported by winds to the study site must be rather small. Previous studies suggested the significantly low amounts of tephra transported towards Greenland prevent finding layers that can be associated with volcanic eruptions (Jennings et al., 2014). After detailed geochemical studies Jennings et al. (2014) could not recognize any specific layer that could be used as a tephrochronological event in the SE Greenland coast during the last millennium. Brown VG fragments are generally solid and not vesicular, suggesting that they are not windblown shards and were more likely to have been incorporated in the ice from outcrops in Greenland and Iceland. Similar brown VG fragments were described in Kangerdlugssuaq trough sediments and were interpreted as coming from the glaciers and sea ice from the Geikie Plateau area, based on mineralogical and X-ray diffraction analysis data (Alonso-Garcia et al., 2013).

The presence of HSGs in Eirik Drift sediments indicates drift ice (sea ice and icebergs) coming from NE Greenland and the Arctic, where red sandstones outcrop (Bond et al., 1997; Henriksen et al., 2009). Most of the glaciers in NE Greenland and the Arctic develop floating ice tongues in the fjords where semi-permanent fast ice hinders the icebergs from drifting. As a result, most of the IRD carried at the base of the icebergs is deposited in the fjords (Reeh et al., 2001). Our HSG record from the Eirik Drift shows a significant amount (up to $30 \%$ ) of this type of IRD. Therefore, despite substantial deposition of debris within the fjords, the remainder of the drifted ice still carries considerable amounts of IRD. We suggest that some of that IRD may have been wind-blown to the top of the glaciers and/or sea ice at the $\mathrm{NE}$ 
Greenland and Arctic coasts and fjords, rather than directly incorporated in the bottom layers of the glacier. Those grains were then ice-rafted southwards by the EGC when the ice was released from the fjords. A similar origin was proposed for HSGs deposited at the SE Greenland coast based on a multi-proxy study (Alonso-Garcia et al., 2013). In that study, periods of high HSG abundance were associated with strong ice export from the Arctic via the EGC.

Variations in Arctic ice export show a significant correlation with Arctic Oscillation (AO) during the last decades (Mysak, 2001; Rigor et al., 2002), with higher Arctic ice export during intervals of positive $\mathrm{AO}$, although this correlation is not so straightforward because Arctic ice export also depends on the meridional wind components and the position of the atmospheric pressure centres (Hilmer and Jung, 2000), and large anomalies in ice export may have a different origin (Lehner et al., 2013). Darby et al. (2012) demonstrated that the sources of Arctic sea ice may change following the $\mathrm{AO}$, and therefore we can observe changes in the mineralogy transported by the ice in sediment cores influenced by the EGC. During the negative state of the AO a strong high-pressure system dominates the Beaufort Sea restricting the Transpolar Drift to the Siberian side of the Arctic Ocean (Mysak, 2001; Rigor et al., 2002), which would bring drift ice with HSGs from the areas of Severnaya Zemlya and Franz Josef Land. The increase in HSG relative abundance and concentration at Eirik Drift after AD 1400 (Fig. 3) may be driven by an intensification in ice export from those areas in the Arctic and northern Greenland rich in HSGs, very likely favoured by atmospheric changes which promoted higher pressures in the Arctic. The increase in HSGs coincides with a shift observed in the sodium concentration $\left(\mathrm{Na}^{+}\right.$, Fig. 3) in Greenland ice core GISP2 (Meeker and Mayewski, 2002), which was interpreted as an increase in storminess by $\sim$ AD 1400. Enhanced storminess favours the transport of icebergs and sea ice through the EGC as well as the deposition of HSGs in the sea ice and on top of glaciers, and both processes increase the number of HSGs transported to Eirik Drift. Greenland temperature also shows a decreasing trend after $\sim$ AD 1400 (Kobashi et al., 2010). The sedimentary record of Feni Drift (Bond et al., 2001), in the NE Atlantic, also shows an increase in HSG relative abundance during the LIA interval (Fig. 3). Colder atmospheric temperatures and the increase in ice drifted from the Arctic may have contributed to decrease subpolar sea surface temperature, favouring icebergs to reach areas further south such as Feni Drift (Bond et al., 2001).

Coal-bearing sediments are present at many areas around the Arctic such as Siberia, northern Canada, Greenland and Scandinavia (Polar Region Atlas, 1978; Petersen et al., 2013) and contribute to high-latitude IRD deposition (Bischof and Darby, 1997; McManus et al., 1996). Even though the percentage of coal fragments is rather low at our study site (under $5 \%$; see Fig. 2) the higher abundance of coal fragments in the Labrador Sea during the MCA may be related to an increase in drift ice from the Canadian Arctic during the positive state of NAO/AO. However, these fragments might also indicate human-related activity which increased in the area during the MCA. Further analysis should be performed to assess the linkage of those grains to any specific source.

Regardless of the mineralogy of the grains, it is worth noting the high number of lithics per gram of sediment recorded in several samples during the MCA (Fig. 2). A recent comprehensive study of the last 2 millennia (PAGES 2k Consortium, 2013) shows this interval presented sustained warm temperatures from AD 830 to 1100 in the Northern Hemisphere, including the Arctic region. The high occurrence of IRD from AD 1000 to 1250 suggests that during the MCA either a substantial amount of icebergs drifted to the study area or the drifting icebergs contained considerable amounts of IRD, or a combination of both explanations. Several studies on East Greenland glaciers and fjords point to the consistent relationship between calving rate acceleration and the presence of warm Atlantic water in East Greenland fjords, brought by the Irminger Current (Andresen et al., 2012; Jennings and Weiner, 1996). Warm atmospheric temperatures as well as the presence of Atlantic water prevent the formation of sea ice in the fjords and in front of the glacier, thus increasing the calving rate by destabilizing the glacier tongue (Andresen et al., 2012; Murray et al., 2010). When tidewater glaciers are released from the sea ice, their speed increases due to the decreased flow resistance and increased alongflow stresses during the retreat of the ice front, and rapid changes may be observed in calving rates in response to disequilibrium at the front (Joughin et al., 2008). At present, Kangerdlugssuaq and Helheim glaciers, located in the central East Greenland coast, represent the $35 \%$ of East Greenland's total discharge (Rignot and Kanagaratnam, 2006). If conditions during the MCA were similar to or warmer than present, the calving rates of these glaciers may have been even higher than at present, delivering vast numbers of icebergs to the EGC, where they would release IRD as they melted. Moreover, during the MCA it is likely that other fjords, such us Nansen and Scoresby Sund, were also ice free during the summer, allowing them to contribute considerable numbers of icebergs to the EGC. The massive diamicton found in Nansen fjord sediments between AD 730 and 1100 demonstrates that there was continuous iceberg rafting due to warmer conditions (Jennings and Weiner, 1996). In this context, we postulate that warm temperatures were the driver of the increased iceberg calving at Greenland fjords and the high accumulation of IRD at Eirik Drift during late MCA.

After AD 1250 several spikes of high IRD abundance occurred during the intervals AD 1400-1450, 1650-1700 and 1750-1800 (Fig. 2). Because those intervals occurred within the LIA and under cold conditions, the trigger of iceberg production must have been slightly different from the drivers proposed for the MCA ice-rafting events. These intervals of high IRD accumulation during the LIA are characterized 
by slightly lower relative abundance of HSGs and higher relative abundance of volcanic grains and other fragments. This points to an intensification of SE Greenland production of icebergs during the LIA intervals of enhanced ice rafting. Therefore, for the LIA events, we advocate for the same mechanism that was put forward to explain rapid releases of icebergs in Denmark Strait during the last 150 years (Alonso-Garcia et al., 2013). During cold periods sea ice becomes perennial along the Greenland coast, blocking the seaward advance of glaciers and hindering icebergs from calving, thus leading to the accumulation of ice mass in the fjords. Based on model simulations, when the sea ice opens or breaks, the ice flow at the grounding line accelerates very quickly, triggering a rapid release of the grounded ice stream (Mugford and Dowdeswell, 2010). In summary, we propose that the high IRD occurrence during the intervals AD 1350$1450,1650-1700$ and $1750-1800$ very likely corresponds to episodes of rapid iceberg release from SE Greenland fjords. Interestingly, the timing of these intervals of high IRD deposition coincides with the intervals of most negative volcanicsolar forcing described by the PAGES $2 \mathrm{k}$ Consortium (2013).

\subsection{Influence of ice rafting on SPG conditions and climate during the last millennium}

Our IRD records have been compared with other palaeoceanographic and palaeoclimatic records from Eirik Drift and other subpolar North Atlantic sites to obtain a better picture of subpolar conditions during the last millennium. The planktonic foraminifer $\delta^{18} \mathrm{O}$ record of $N$. pachyderma $\sin$ from Eirik Drift (this study) indicates slightly lower temperatures after AD 1050 (Fig. 4i). A study from the same region presented a $\delta^{18} \mathrm{O}$ record of Globigerina bulloides (Fig. 4i) and relative abundance of $N$. pachyderma sinistral (Fig. 4h) (Moffa-Sanchez et al., 2014a, b), which suggest a cooling episode during late MCA ( AD 1100) and a clear drop in temperature after $\mathrm{AD} 1200$. The coincidence of these temperature drops with the increasing trend in total IRD concentration at site GS06-144-03 indicates that the growing iceberg production at East Greenland fjords, due to the MCA warm conditions, started to cool and freshen Labrador Sea several centuries before the LIA started. The quartz/plagioclase ratio, a bulk measure of IRD (Moros et al., 2004), also shows an increasing trend at the end of the MCA at sites in Denmark Strait (Andrews et al., 2009; see Fig. 4j) and off northern Iceland (Moros et al., 2006), providing further evidence for the intensification of iceberg calving at this time. Colder winter sea surface conditions have also been recorded off $\mathrm{N}$ Iceland after AD 1200 (Jiang et al., 2007; see Fig. 4f), although sea surface conditions were not cold enough to generate long seasons of severe sea ice until AD 1300 (Massé et al., 2008; see Fig. 4e), when annual SST had substantially decreased (Sicre et al., 2008). SE Greenland sea ice and SST proxies (Fig. 3a and b) indicate an increase in sea ice and SST decrease at $\sim$ AD 1200 (Miettinen et al., 2015). The re-

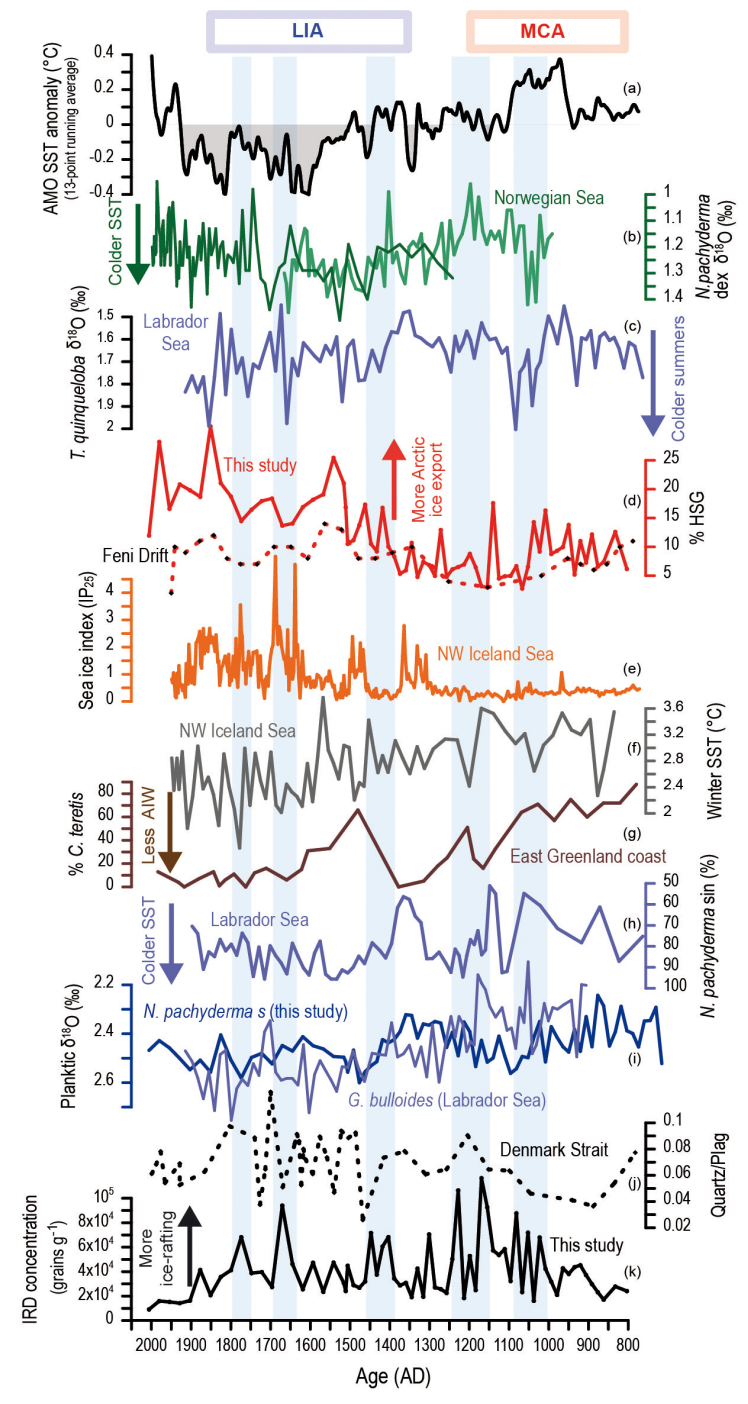

Figure 4. Comparison of IRD records from site GS06-144-03 with subpolar North Atlantic records of sea surface temperature, ice rafting and sea ice. (a) Atlantic Multidecadal Oscillation (AMO) SST anomaly (Mann et al., 2009); (b) N. pachyderma dex $\delta^{18} \mathrm{O}$ record from the Norwegian Sea (Sejrup et al., 2010); (c) T. quinqueloba $\delta^{18} \mathrm{O}$ record from site RAPiD-35-25B at Eirik Drift; (d) HSG relative abundance from site GS06-144-03 (solid line, this study) and from Feni Drift (dashed line; Bond et al., 2001); (e) sea ice index (IP25) from site MD99-2275, NW of Iceland (Massé et al., 2008); (f) diatom-based winter SST from site MD99-2275 (Jiang et al., 2007); (g) relative abundance of the Atlantic waters indicator Cassidulina teretis from Nansen Fjord (Jennings and Weiner, 1996); (h) relative abundance of $N$. pachyderma sin from Eirik Drift (Moffa-Sanchez et al., 2014b); (i) planktic foraminifer $\delta^{18} \mathrm{O}$ from Eirik Drift ( $G$. bulloides from Moffa-Sanchez et al., 2014a; $N$. pachyderma sin from this study); (j) quartz vs. plagioclase ratio, a proxy for ice rafting, from MD99-2263 (Andrews et al., 2009); and (k) total IRD concentration from site GS06-144-03 (this study). Light-blue vertical bars indicate the periods in which IRD concentration is higher at site GS06-144-03. 
duction in the relative abundance of the benthic foraminifer Cassidulina teretis between AD 1000 and 1300 in Nansen fjord indicates a weaker influence of Atlantic water at the East Greenland coast (Jennings and Weiner, 1996). This decline in Atlantic water may be explained by a weakening in the northern branch of the Irminger current which would have favoured the SST decrease and sea ice formation in SE Greenland coast and in Denmark Strait and north of Iceland. Blindheim and Malmberg (2005) associated the northern Irminger current weakening with high pressure over Greenland and weaker northerly winds. In addition, the mineralogical composition and biomarker study of the last 2000 years in several sites in Denmark Strait and north of Iceland indicate a change to cold conditions at $\sim$ AD 1250 very likely associated with an intensification of the high pressure over Greenland and the strengthening of N and NW winds, which led to progressive presence of sea ice exported from the Arctic during winter and spring (Andrews et al., 2009).

The anomalously high Atlantic temperatures recorded during the interval AD 950-1100 (Mann et al., 2009) may indicate SPG circulation was in the strong mode during that time interval (Figs. 4a and 5c). Strong SPG circulation enhances the supply of warm Atlantic Intermediate water to the East Greenland coast, which promotes calving and, subsequently, increases the ice input in the Labrador Sea region. Switches from weak to strong SPG circulation may happen naturally due to external or internal forcings, and these changes are currently a matter of debate because of their influence on North Atlantic climate (e.g. Hakkinen and Rhines, 2004). According to model simulations, freshwater input (i.e. ice input) to the SPG may trigger weakening of SPG circulation, and this may be amplified successively by positive feedbacks resulting in further weakening and freshening of the gyre due to the attenuation of the Irminger Current (Born et al., 2010, 2016; Moreno-Chamarro et al., 2017). Specifically for this time interval, it is important that the main freshwater input reached the Labrador Sea, affecting deep water formation, because a freshwater input into the Nordic Seas may have driven the opposite effect (Born and Stocker, 2014). Our IRD record demonstrates an increase in the amount of ice transported by the EGC to the Labrador Sea from AD 1000 to 1250 , with a potential main source in SE Greenland. This input of freshwater to the SPG potentially drove a slowdown of deep convection in this area and weakened the SPG circulation. A recent study also points to enhanced input of the Labrador Current to the Labrador Sea from AD 1000 to 1300 (Sicre et al., 2014), which indicates calving intensified in SW Greenland and Baffin Bay regions as well. It is likely that ice from both sources, East and West Greenland, directly affected the salinity balance of Labrador Sea water and deep convection in this region. However, even though the freshwater input started at $\sim$ AD 1000, the SPG circulation only started to weaken after $\sim$ AD 1250, as suggested by a record of deep-sea corals from the NE Atlantic (Copard et al., 2012). Moreover, our IRD data show a lag between the first temperature drops at Eirik Drift and the decrease in ice rafting (Fig. 4), indicating a delay between SPG weakening and Irminger Current slowdown. It seems the SPG entered in the weak mode, because of the reduced convection, but warm intermediate water remained in the fjords for several years, allowing continued iceberg calving. Also, the response of calving may be slower, particularly if SSTs were relatively warm and the fjords were not perennially covered by sea ice. However, simulations to reconstruct past climate changes normally are not detailed enough to characterize the impact of direct freshwater input from Greenland to the ocean, and its consequences after several years to decades, which would be very interesting to better understand past climate events as the LIA.

As the strength of Irminger Current input declined, the areas of SE Greenland, Denmark Strait and north of Iceland cooled, and coastal sea ice became perennial after AD 1450, according to the sea ice index $\mathrm{IP}_{25}$ (Massé et al., 2008). The $\delta^{18} \mathrm{O}$ records of $N$. pachyderma sinistral (Fig. 4i, this study) and Turborotalita quinqueloba (Fig. 4c) from Eirik Drift (Moffa-Sanchez et al., 2014b) indicate a shift to colder summer SST in the SPG after AD 1400 (Fig. 4), which coincides with the increase in Arctic ice export reflected by the HSGs, and the storminess intensification (Fig. 3c), recorded by the $\mathrm{Na}^{+}$content in the Greenland ice core GISP (Meeker and Mayewski, 2002). Planktic $\delta^{18} \mathrm{O}$ and $\mathrm{Mg} / \mathrm{Ca}$ from sites in the Norwegian Sea (Fig. 4b) display an initial decrease in temperature at AD 1200, and a subsequent distinct downward shift at $\sim$ AD 1400, which suggests not only SST cooling but also a decline in the stratification of the water column, very likely linked to changes in the upper-ocean conditions in this region as well (Nyland et al., 2006; Sejrup et al., 2010).

It is clear that sea surface conditions in the SPG were rather different before and after $\sim \mathrm{AD} 1200$. The freshening of the SPG and the increase in sea ice along the Greenland and Iceland coasts may have been associated with a change in atmospheric conditions, weakening winter circulation over the Arctic and promoting more storminess in the subpolar area and the development of atmospheric blocking events (Moreno-Chamarro et al., 2017). Model simulations point to the development of frequent and persistent atmospheric blocking events, induced by low solar irradiance, as one of the main drivers to develop the consecutive cold winters documented in Europe during the LIA (Barriopedro et al., 2008; Moffa-Sanchez et al., 2014a). Atmospheric blocking events derive from instabilities of the jet stream which divert or block the pathway of the westerly winds (Häkkinen et al., 2011). These events typically predominate during winter and occur linked to high pressure in the Arctic and a weak polar vortex. The cold SST events recorded at the subpolar area during the last millennium (Moffa-Sanchez et al., 2014a, b; Sejrup et al., 2010) suggest that atmospheric blocking events affected the entire North Atlantic regional climate. 


\subsection{Implications for LIA origin and Norse colonies}

It is worth noting that our IRD record shows two types of ice-rafting events: ice rafting related to warm temperatures (during the MCA), and ice rafting linked to rapid releases of the ice accumulated in the fjords due to cold conditions (during the LIA). During the LIA, the events of maximum ice rafting are coherent with the minimum values of solar irradiance (Steinhilber et al., 2009), particularly with the Wolf, Spörer, and Maunder minima (Fig. 5). Ice-rafting events in our record tend to happen during intervals of low solar irradiance and cold temperatures in the SPG, often with also significantly cold summer SST (Fig. 4c and i). The reconstruction of radiative forcing based on solar irradiance and volcanic eruptions (Sigl et al., 2015) also shows low values during the main events of high IRD occurrence (Fig. 5).

Solar irradiance has been put forward as the main trigger for the Holocene cold events because low solar irradiance induces an atmospheric reorganization in the polar region which affects not only the North Atlantic but also the midlatitudes of the Northern Hemisphere (e.g. Bond et al., 2001). Several records from the high-latitude North Atlantic support this hypothesis, displaying cold temperatures at times of solar irradiance minima during the last millennium (MoffaSanchez et al., 2014a; Sejrup et al., 2010). However, the role of solar irradiance on forcing cooling events has been questioned during the last decade. A comprehensive review on the topic proposed that a combination of internal climate variability and external forcings contributed to drive Holocene cold events, including the LIA (Wanner et al., 2011). Volcanic activity is also commonly put forward as the main driver of atmospheric reorganizations which derived in cooling events. Precisely dated records of ice-cap growth from Arctic Canada and Iceland (Miller et al., 2012) showed that LIA summer cooling and ice growth, potentially linked to volcanic forcing, began abruptly between AD 1275 and 1300, followed by a substantial intensification at AD 1430-1455. Moreover, a recent study about the role of radiative forcings and climate feedbacks on global cooling over the last millennium also concluded that the volcanic forcing is the factor that contributed the most (Atwood et al., 2016).

According to our observations, the increase in Greenland calving during the MCA (Fig. 5e) took place before the ice caps started to grow, during an interval of high solar irradiance (Fig. 5f), high temperatures in the Northern Hemisphere (Fig. 5c), and low volcanic activity (Fig. 5g). This indicates that the ice-rafting events of the MCA were not related to the fluctuations driven by solar-volcanic forcing. Alternatively, we interpret these events as resulting from the acceleration of calving rates in SE Greenland glaciers, driven by warm temperatures. We postulate that the increase in calving rates during the MCA induced a decrease in the Labrador Sea salinity, which may have triggered the weakening of SPG circulation and reduced convection. A decline in Labrador Sea convection reduces deep water formation in one of the key areas

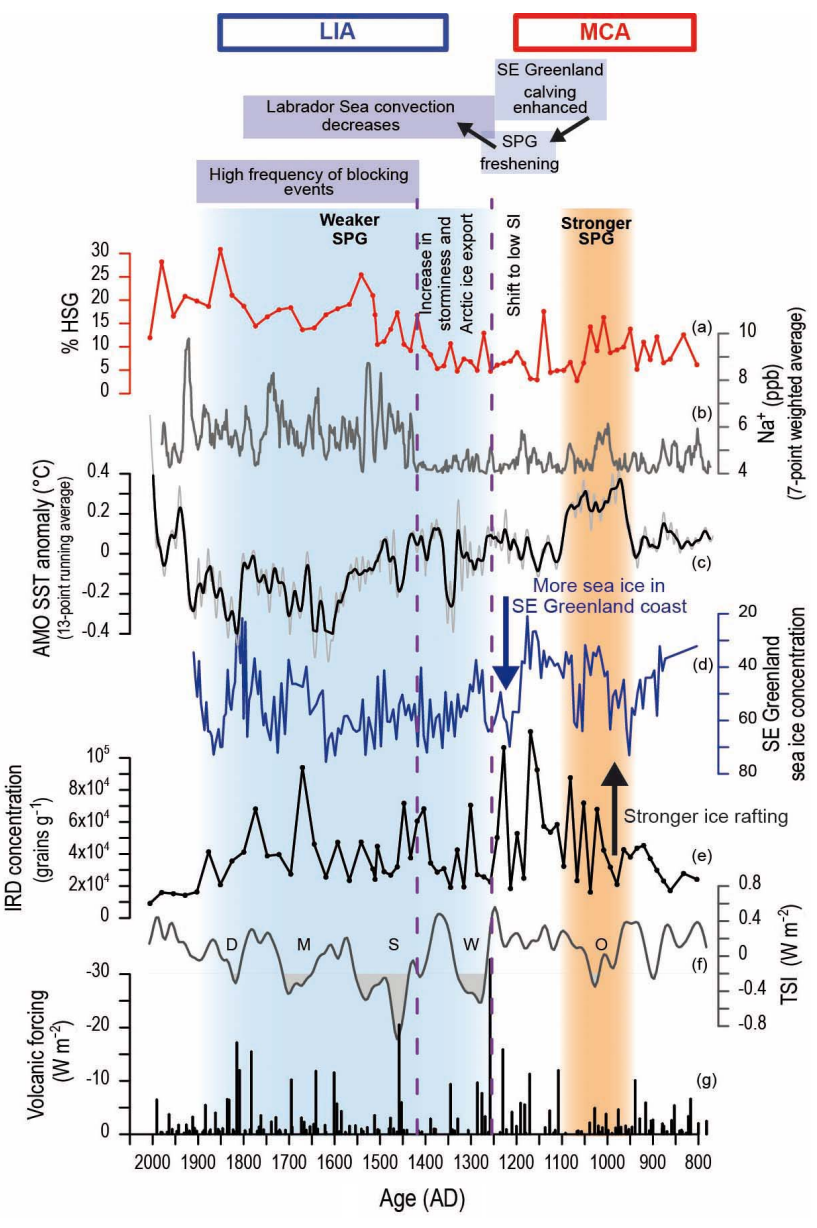

Figure 5. Sequence of events during the transition from the MCA to LIA and linkage to potential forcings. (a) Hematite-stained grains (HSGs) relative abundance at site GS06-144-03; (b) $\mathrm{Na}^{+}$record from GISP2 (Meeker and Mayewski, 2002); (c) Atlantic Multidecadal Oscillation (AMO) SST anomaly (Mann et al., 2009); (d) SE Greenland April sea ice concentration (Miettinen et al., 2015); (e) total IRD concentration at site GS06-144-03; (f) reconstruction of total solar irradiance based on ${ }^{10} \mathrm{Be}$ isotopes from ice cores (Steinhilber et al., 2009); and (g) radiative forcing based on volcanic eruption reconstructions (Sigl et al., 2015). During the interval shaded in red SPG circulation was stronger, according to the interpretations of this work, whereas during the interval shaded in blue SPG circulation was weaker. The letters in the solar irradiance record indicate the minima of solar irradiance named Oort $(\mathrm{O})$, Wolf (W), Spörer (S), Maunder (M), and Dalton (D).

of the North Atlantic, which weakens North Atlantic circulation and, in turn, decreases oceanic heat transport to this area (Born et al., 2010; Moreno-Chamarro et al., 2017). Once the SPG entered in the weak mode, this area received less heat and became more sensitive to external forcings which may have generated further cooling. This interpretation is in agreement with recent model simulations which suggest that a weakening of the SPG circulation could have induced the LIA cooling, and this shift from strong to weak circulation 
may have been triggered by freshwater input to the Labrador Sea (Moreno-Chamarro et al., 2017). Subsequently, low solar irradiance intervals, possibly combined with volcanic emissions, promoted atmospheric reorganizations which gave rise to a weakening of the polar vortex and promoted atmospheric blocking events, enhancing cold temperatures in the subpolar area and leading to ice sheet growth in the Arctic region during the LIA. The development of atmospheric blocking events in the North Atlantic, as suggested by Moffa-Sanchez et al. (2014a), probably propagated the atmospheric cooling across Europe and the Nordic Seas. Indeed, the first strong minimum of solar irradiance during the last millennium (Wolf, AD 1300) occurred when the Labrador Sea was already fresher and SPG circulation was weak (Fig. 5), according to our interpretations and to Copard et al. (2012) deep-sea corals record. The reconstructions of solar and volcanic forcings (Fig. 5f and g) shows a trend of lower values after AD 1450 with a first step of low values during the Wolf minimum, indicating that volcanic forcing may also have played an important role in modifying the atmospheric conditions. However, we consider that the decrease in Labrador Sea salinity prior to the Wolf minimum was crucial to produce changes in SPG circulation. Once the SPG entered the weak mode, the effects of solar and volcanic forcing possibly produced a deeper impact on North Atlantic climate. It is likely that the LIA would not have been such a cold and widespread event if the SPG circulation was strong and deep convection was active at the time.

The results of this study can be linked to the expansion and demise of the Norse colonies. According to historical data, the Norse expansion and colonization of Iceland and Greenland occurred during the warmer climate conditions of the MCA which favoured fishing and farming in these regions (Kuijpers et al., 2014; Ogilvie et al., 2000; Ogilvie and Jónsson, 2001; see Fig. 3). Our study indicates that, even though calving intensified after the settlement of the Norse colonies in Greenland, climatic conditions during the late MCA were still favourable because the strong circulation in the SPG supplied relatively warm water to SE Greenland coast. Therefore, the fjords were not perennially covered by sea ice and it is likely that a rather continuous calving may have helped hunting. However, after several decades of intense calving and melting of Greenland glaciers, the Labrador Sea became fresher and the SPG circulation started to weaken, triggering a change in oceanic and atmospheric conditions. The reduction of deep convection decreased the transport of heat to the NW subpolar area and enhanced sea ice occurrence in the fjords, which deteriorated the living conditions in Greenland. The subsequent cooling and increase in storminess brought by the shift in atmospheric conditions (increase in atmospheric blocking events) very likely favoured the abandonment of the Greenland Norse settlements at the beginning of the LIA (Dugmore et al., 2012; Ogilvie et al., 2000, Fig. 3).

\section{Conclusions}

Sediments from Eirik Drift were studied in order to examine the variations in ice rafting during the last millennium and its linkage to LIA development. IRD in the 63-150 $\mu \mathrm{m}$ fraction shows the highest concentration during the intervals $\sim$ AD 1000-1100, 1150-1250, 1400-1450, $\sim 1650-1700$ and $\sim 1750-1800$. The identification of different minerals allowed us to link the IRD with potential sources and better interpret the ice-rafting events. The main IRD source was along the SE Greenland coast, although during the LIA the greater concentration and relative abundance of HSGs support an increase in the contribution of ice exported from the Arctic region and NE Greenland via the EGC. Two different types of ice-rafting events have been recognized: (1) ice rafting recorded during the MCA, which we interpret as being related to the acceleration of calving rates in SE Greenland glaciers driven by warm oceanic and atmospheric temperature and (2) ice rafting events during the LIA, which have been linked to rapid releases of the ice accumulated in the fjords due to the perennial sea ice developed in the Greenland coast during cold periods.

The comparison of our IRD records with other North Atlantic reconstructions of ice rafting, sea surface, and deep ocean conditions provides a better picture of the development of the LIA in the subpolar region. We postulate that the enhanced ice discharge during the MCA, due to warm conditions, decreased sea surface salinity in the Labrador Sea, which in turn reduced Labrador Sea convection and weakened SPG circulation. The reduction in convection in the Labrador Sea, one of the key areas of deep water formation in the North Atlantic, potentially weakened the North Atlantic circulation and decreased oceanic heat transport to the high latitudes, particularly to the Labrador Sea region. In other words, the reduced convection also diminished the arrival of warm water from the NAC to SE Greenland coasts, inducing perennial sea ice occurrence and cooling the atmosphere which promoted ice sheet growth in the Arctic. The subsequent atmospheric and oceanographic reorganizations induced by external forcings, such as solar and volcanic forcing, generated extremely cold conditions in the North Atlantic during the LIA, with the development of atmospheric blocking events which boosted further cooling and harsh conditions across Europe and the Nordic Seas, and led the Norse to abandon their colonies in Greenland around AD 1400 because of their maladaptation to cold climate conditions (Dugmore et al., 2012).

This study puts forward the idea that the development of the exceptionally cold conditions during the LIA may be better explained by the previous freshening of the Labrador Sea due to enhanced ice rafting during the MCA and the subsequent weakening of the SPG circulation. This finding may be fundamental to model future climate conditions given that calving in the SE Greenland glaciers has been increasing dur- 
ing the last decade (Andresen et al., 2012; Straneo et al., 2013).

Data availability. Data can be obtained from Pangaea at https://doi.pangaea.de/10.1594/PANGAEA.874286 (AlonsoGarcia, 2017).

Competing interests. The authors declare that they have no conflict of interest.

Acknowledgements. This project was funded by NSF grants OCE-0961670 and OCE-1258984, and the Comer Science and Education Foundation grant CP75. The authors would like to thank the reviewers and editor for their insightful comments which contributed to improving the manuscript. Tony Greco is acknowledged for analytical support with the SEM analysis. M. Alonso-Garcia would like to acknowledge the support from A. E. Shevenell, J. Dixon, and D. Hollander during her postdoc at USF, and funding from Portuguese National Science and Technology Foundation (FCT) through the postdoctoral fellowship SFRH/BPD/96960/2013 and CCMAR funds UID/Multi/04326/2013.

Edited by: A. Dutton

Reviewed by: J. Andrews and two anonymous referees

\section{References}

Alonso-Garcia, M., Andrews, J. T., Belt, S. T., Cabedo-Sanz, P., Darby, D., and Jaeger, J.: A comparison between multiproxy and historical data (AD 1990-1840) of drift ice conditions on the East Greenland shelf $\left(\sim 66^{\circ} \mathrm{N}\right)$, The Holocene, 23, 1672-1683, 2013.

Alonso-Garcia, M., Kleiven, H. F., McManus, J. F., Moffa-Sanchez, P., Broecker, W. S., and Flower, B. P.: Ice-rafing history in the Labrador Sea during the last millennium. Dataset \#874286 (DOI registration in progress), https://doi.pangaea.de/10.1594/ PANGAEA.874286, 2017.

Andresen, C. S., Straneo, F., Ribergaard, M. H., Bjork, A. A., Andersen, T. J., Kuijpers, A., Norgaard-Pedersen, N., Kjaer, K. H., Schjoth, F., Weckstrom, K., and Ahlstrom, A. P.: Rapid response of Helheim Glacier in Greenland to climate variability over the past century, Nat. Geosci., 5, 37-41, 2012.

Andrews, J. T.: Icebergs and iceberg rafted detritus (IRD) in the North Atlantic: Facts and assumptions, Oceanography, 13, 100$108,2000$.

Andrews, J. T., Belt, S. T., Olafsdottir, S., Massé, G., and Vare, L. L.: Sea ice and marine climate variability for NW Iceland/Denmark Strait over the last 2000 cal. yr BP, The Holocene, 19, 775-784, 2009.

Andrews, J. T., Bigg, G. R., and Wilton, D. J.: Holocene ice-rafting and sediment transport from the glaciated margin of East Greenland $\left(67-70^{\circ} \mathrm{N}\right)$ to the $\mathrm{N}$ Iceland shelves: detecting and modelling changing sediment sources, Quaternary Sci. Rev., 91, 204217, 2014.

Atwood, A. R., Wu, E., Frierson, D. M. W., Battisti, D. S., and Sachs, J. P.: Quantifying Climate Forcings and Feedbacks over the Last Millennium in the CMIP5-PMIP3 Models, J. Climate, 29, 1161-1178, 2016.

Bailey, I., Foster, G. L., Wilson, P. A., Jovane, L., Storey, C. D., Trueman, C. N., and Becker, J.: Flux and provenance of icerafted debris in the earliest Pleistocene sub-polar North Atlantic Ocean comparable to the last glacial maximum, Earth Planet. Sc. Lett., 341-344, 222-233, 2012.

Barriopedro, D., García-Herrera, R., and Huth, R.: Solar modulation of Northern Hemisphere winter blocking, J. Geophys. Res.Atmos., 113, D14118, doi:10.1029/2008JD009789, 2008.

Bischof, J. F. and Darby, D. A.: Mid- to Late Pleistocene Ice Drift in the Western Arctic Ocean: Evidence for a Different Circulation in the Past, Science, 277, 74-78, 1997.

Blindheim, J. and Malmberg, S. A.: The mean sea level pressure gradient across the Denmark Strait as an indicator of conditions in the North Icelandic Irminger current, in: The Nordic Seas: An Integrated Perspective Oceanography, Climatology, Biogeochemistry, and Modeling, Geophys. Monogr. Ser., AGU, Washington, DC, 2005.

Bond, G., Showers, W., Cheseby, M., Lotti, R., Almasi, P., deMenocal, P., Priore, P., Cullen, H., Hajdas, I., and Bonani, G.: A Pervasive Millennial-Scale Cycle in North Atlantic Holocene and Glacial Climates, Science, 278, 1257-1266, 1997.

Bond, G., Kromer, B., Beer, J., Muscheler, R., Evans, M. N., Showers, W., Hoffmann, S., Lotti-Bond, R., Hajdas, I., and Bonani, G.: Persistent Solar Influence on North Atlantic Climate During the Holocene, Science, 294, 2130-2136, 2001.

Bond, G. C. and Lotti, R.: Iceberg Discharges into the North Atlantic on Millennial Time Scales During the Last Glaciation, Science, 267, 1005-1010, 1995.

Böning, C. W., Scheinert, M., Dengg, J., Biastoch, A., and Funk, A.: Decadal variability of subpolar gyre transport and its reverberation in the North Atlantic overturning, Geophys. Res. Lett., 33, L21S01, doi:10.1029/2006GL026906, 2006.

Born, A. and Stocker, T. F.: Two Stable Equilibria of the Atlantic Subpolar Gyre, J. Phys. Oceanogr., 44, 246-264, 2014.

Born, A., Nisancioglu, K., and Braconnot, P.: Sea ice induced changes in ocean circulation during the Eemian, Clim. Dynam., 35, 1361-1371, 2010.

Born, A., Stocker, T. F., and Sandø, A. B.: Transport of salt and freshwater in the Atlantic Subpolar Gyre, Ocean Dynam., 66, 1051-1064, 2016.

Born, A. and Stocker, T. F.: Two Stable Equilibria of the Atlantic Subpolar Gyre, J. Phys. Oceanogr., 44, 246-264, 2014.

Bradley, R. S., Briffa, K. R., Cole, J., Hughes, M. K., and Osborn, T. J.: The climate of the last millennium, in: Paleoclimate, global change and the future, Springer, 2003.

Copard, K., Colin, C., Henderson, G. M., Scholten, J., Douville, E., Sicre, M. A., and Frank, N.: Late Holocene intermediate water variability in the northeastern Atlantic as recorded by deep-sea corals, Earth Planet. Sc. Lett., 313-314, 34-44, 2012.

Darby, D. A., Ortiz, J. D., Grosch, C. E., and Lund, S. P.: 1,500year cycle in the Arctic Oscillation identified in Holocene Arctic sea-ice drift, Nat. Geosci., 5, 897-900, 2012.

Dickson, R. R., Meincke, J., Malmberg, S.-A., and Lee, A. J.: The "great salinity anomaly" in the Northern North Atlantic 19681982, Prog. Oceanogr., 20, 103-151, 1988.

Dokken, T. and Ninnemann, U.: Cruise Report R/V G.O. Sars, UoB Cruise No: GS06-144, 2006. 
Dugmore, A. J., McGovern, T. H., Vésteinsson, O., Arneborg, J., Streeter, R., and Keller, C.: Cultural adaptation, compounding vulnerabilities and conjunctures in Norse Greenland, P. Natl. Acad. Sci. USA, 109, 3658-3663, 2012.

Fillon, R. H., Miller, G. H., and Andrews, J. T.: Terrigenous sand in Labrador Sea hemipelagic sediments and paleoglacial events on Baffin Island over the last 100, 00 years, Boreas, 10, 107-124, 1981.

Gao, C., Robock, A., and Ammann, C.: Volcanic forcing of climate over the past 1500 years: An improved ice core-based index for climate models, J. Geophys. Res., 113, D23111, doi:10.1029/2008JD010239, 2008.

Grönvold, K., Óskarsson, N., Johnsen, S. J., Clausen, H. B., Hammer, C. U., Bond, G., and Bard, E.: Ash layers from Iceland in the Greenland GRIP ice core correlated with oceanic and land sediments, Earth Planet. Sc. Lett., 135, 149-155, 1995.

Hakkinen, S. and Rhines, P. B.: Decline of Subpolar North Atlantic Circulation During the 1990s, Science, 304, 555-559, 2004.

Häkkinen, S., Rhines, P. B., and Worthen, D. L.: Atmospheric blocking and Atlantic multidecadal ocean variability, Science, 334, 655-659, 2011.

Hatun, H., Sando, A. B., Drange, H., Hansen, B., and Valdimarsson, H.: Influence of the Atlantic Subpolar Gyre on the Thermohaline Circulation, Science, 309, 1841-1844, 2005.

Henriksen, N., Higgins, A. K., Kalsbeek, F., and Pulvertaft, T. C. R.: Greenland from Archaean to Quaternary. Descriptive text to the 1995 Geological map of Greenland, 1:2500000. 2nd edition, Geol. Surv. Den. Greenl., 18, 126 pp. + map, 2009.

Hilmer, M. and Jung, T.: Evidence for a recent change in the link between the North Atlantic Oscillation and Arctic Sea ice export, Geophys. Res. Lett., 27, 989-992, 2000.

Hughen, K. A., Baillie, M. G., Bard, E., Beck, J. W., Bertrand, C. J., Blackwell, P. G., Buck, C. E., Burr, G. S., Cutler, K. B., and Damon, P. E.: Marine04 marine radiocarbon age calibration, 026 cal kyr BP, Radiocarbon, 46, 1059-1086, 2004.

Jennings, A., Thordarson, T., Zalzal, K., Stoner, J., Hayward, C., Geirsdóttir, Á., and Miller, G.: Holocene tephra from Iceland and Alaska in SE Greenland shelf sediments, Geological Society, London, Special Publications, 398, SP398, 396, 2014.

Jennings, A. E. and Weiner, N. J.: Environmental change in eastern Greenland during the last 1300 years: evidence from foraminifera and lithofacies in Nansen Fjord, $68^{\circ} \mathrm{N}$, The Holocene, 6, 179-191, 1996.

Jiang, H., Ren, J., Knudsen, K., Eiríksson, J., and Ran, L.: Summer sea-surface temperatures and climate events on the North Icelandic shelf through the last 3000 years, Chin. Sci. Bull., 52, 789-796, 2007.

Joughin, I., Howat, I., Alley, R. B., Ekstrom, G., Fahnestock, M., Moon, T., Nettles, M., Truffer, M., and Tsai, V. C.: Icefront variation and tidewater behavior on Helheim and Kangerdlugssuaq Glaciers, Greenland, J. Geophys. Res.-Earth, 113, F01004, doi:10.1029/2007jf000837, 2008.

Kobashi, T., Severinghaus, J., Barnola, J.-M., Kawamura, K., Carter, T., and Nakaegawa, T.: Persistent multi-decadal Greenland temperature fluctuation through the last millennium, Clim. Change, 100, 733-756, 2010.

Kuijpers, A., Mikkelsen, N., Ribeiro, S., and Seidenkrantz, M.-S.: Impact of medieval fjord hydrography and climate on the western and eastern settlements in Norse Greenland, Journal of the North Atlantic, 6, 1-13, 2014.

Lacasse, C.: Influence of climate variability on the atmospheric transport of Icelandic tephra in the subpolar North Atlantic, Global Planet. Change, 29, 31-55, 2001.

Lehner, F., Born, A., Raible, C. C., and Stocker, T. F.: Amplified Inception of European Little Ice Age by Sea Ice-OceanAtmosphere Feedbacks, J. Clim., 26, 7586-7602, 2013.

Locarnini, R. A., Mishonov, A. V., Antonov, J. I., Boyer, T. P., Garcia, H. E., Baranova, O. K., Zweng, M. M., Paver, C. R., Reagan, J. R., Johnson, D. R., Hamilton, M., and Seidov, D.: World Ocean Atlas 2013, Volume 1: Temperature, edited by: Levitus, S., A. Mishonov Technical Ed., NOAA Atlas NESDIS 73, 40 pp., 2013.

Manabe, S. and Stouffer, R. J.: Simulation of abrupt climate change induced by freshwater input to the North Atlantic Ocean, Nature, 378, 165-167, 1995.

Mann, M. E., Zhang, Z., Rutherford, S., Bradley, R. S., Hughes, M. K., Shindell, D., Ammann, C., Faluvegi, G., and Ni, F.: Global Signatures and Dynamical Origins of the Little Ice Age and Medieval Climate Anomaly, Science, 326, 1256-1260, 2009.

Massé, G., Rowland, S. J., Sicre, M.-A., Jacob, J., Jansen, E., and Belt, S. T.: Abrupt climate changes for Iceland during the last millennium: Evidence from high resolution sea ice reconstructions, Earth Planet. Sc. Lett., 269, 565-569, 2008.

McManus, J. F., Major, C., Flower, B. P., and Fronval, T.: Variability in sea-surface conditions in the North Atlantic-Arctic gateways during the last 140000 years, in: Proceedings of the Ocean Drilling Program. Scientific results, College Station, TX, edited by: Thiede, J., Myhre, A. M., Firth, J. V., Johnson, G. L., and Ruddiman, W. F., Ocean Drilling Program, v. 151, 1996.

Meeker, L. D. and Mayewski, P. A.: A 1400-year high-resolution record of atmospheric circulation over the North Atlantic and Asia, The Holocene, 12, 257-266, 2002.

Miettinen, A., Divine, D. V., Husum, K., Koç, N., and Jennings, A.: Exceptional ocean surface conditions on the SE Greenland shelf during the Medieval Climate Anomaly, Paleoceanography, 30, 1657-1674, 2015.

Miller, G. H., Geirsdóttir, Á., Zhong, Y., Larsen, D. J., OttoBliesner, B. L., Holland, M. M., Bailey, D. A., Refsnider, K. A., Lehman, S. J., Southon, J. R., Anderson, C., Björnsson, H., and Thordarson, T.: Abrupt onset of the Little Ice Age triggered by volcanism and sustained by sea-ice/ocean feedbacks, Geophys. Res. Lett., 39, L02708, doi:10.1029/2011GL050168, 2012.

Moffa-Sanchez, P., Born, A., Hall, I. R., Thornalley, D. J. R., and Barker, S.: Solar forcing of North Atlantic surface temperature and salinity over the past millennium, Nat. Geosci., 7, 275-278, 2014a.

Moffa-Sanchez, P., Hall, I. R., Barker, S., Thornalley, D. J. R., and Yashayaev, I.: Surface changes in the eastern Labrador Sea around the onset of the Little Ice Age, Paleoceanography, 29, 2013PA002523, doi:10.1002/2013pa002523, 2014b.

Mokeddem, Z. and McManus, J. F.: Persistent climatic and oceanographic oscillations in the subpolar North Atlantic during the MIS 6 glaciation and MIS 5 interglacial, Paleoceanography, 31, 778, doi:10.1002/2015PA002813, 2016.

Mokeddem, Z., McManus, J. F., and Oppo, D. W.: Oceanographic dynamics and the end of the last interglacial in the subpolar North Atlantic, P. Natl. Acad. Sci. USA, 111, 11263-11268, 2014. 
Moreno-Chamarro, E., Zanchettin, D., Lohmann, K., and Jungclaus, J. H.: Internally generated decadal cold events in the northern North Atlantic and their possible implications for the demise of the Norse settlements in Greenland, Geophys. Res. Lett., 42, 908-915, 2015.

Moreno-Chamarro, E., Zanchettin, D., Lohmann, K., and Jungclaus, J. H.: An abrupt weakening of the subpolar gyre as trigger of Little Ice Age-type episodes, Clim. Dynam., 48, 727-744, doi:10.1007/s00382-016-3106-7, 2017.

Moros, M., McManus, J. F., Rasmussen, T., Kuijpers, A., Dokken, T., Snowball, I., Nielsen, T., and Jansen, E.: Quartz content and the quartz-to-plagioclase ratio determined by X-ray diffraction: a proxy for ice rafting in the northern North Atlantic?, Earth Planet. Sc. Lett., 218, 389-401, 2004.

Moros, M., Andrews, J. T., Eberl, D. D., and Jansen, E.: Holocene history of drift ice in the northern North Atlantic: Evidence for different spatial and temporal modes, Paleoceanography, 21, PA2017, doi:10.1029/2005PA001214, 2006.

Moros, M., Jansen, E., Oppo, D. W., Giraudeau, J., and Kuijpers, A.: Reconstruction of the late-Holocene changes in the SubArctic Front position at the Reykjanes Ridge, north Atlantic, The Holocene, 22, 877-886, 2012.

Mugford, R. I. and Dowdeswell, J. A.: Modeling iceberg-rafted sedimentation in high-latitude fjord environments, J. Geophys. Res.Earth, 115, F03024, doi:10.1029/2009jf001564, 2010.

Murray, T., Scharrer, K., James, T. D., Dye, S. R., Hanna, E., Booth, A. D., Selmes, N., Luckman, A., Hughes, A. L. C., Cook, S., and Huybrechts, P.: Ocean regulation hypothesis for glacier dynamics in southeast Greenland and implications for ice sheet mass changes, J. Geophys. Res.-Earth, 115, F03026, doi:10.1029/2009jf001522, 2010.

Mysak, L. A.: Patterns of Arctic Circulation, Science, 293, 12691270, 2001.

Nyland, B. F., Jansen, E., Elderfield, H., and Andersson, C.: Neogloboquadrina pachyderma (dex. and sin.) $\mathrm{Mg} / \mathrm{Ca}$ and $\delta^{18} \mathrm{O}$ records from the Norwegian Sea, Geochem. Geophy. Geosy., 7, Q10P17, doi:10.1029/2005GC001055, 2006.

Ogilvie, A. E. J. and Jónsson, T.: "Little Ice Age” Research: A Perspective from Iceland, Clim. Change, 48, 9-52, 2001.

Ogilvie, A. E. J., Barlow, L. K., and Jennings, A. E.: North Atlantic climate c.ad 1000: Millennial reflections on the Viking discoveries of Iceland, Greenland and North America, Weather, 55, 3445, 2000.

PAGES 2k Consortium: Continental-scale temperature variability during the past two millennia, Nat. Geosci., 6, 339-346, 2013.

Petersen, H. I., Øverland, J. A., Solbakk, T., Bojesen-Koefoed, J. A., and Bjerager, M.: Unusual resinite-rich coals found in northeastern Greenland and along the Norwegian coast: Petrographic and geochemical composition, Int. J. Coal Geol., 109-110, 5876, 2013.

Polar Regions Atlas: Washington, DC, Foreign Assessment Center, Central Intelligence Agency, 1978.

Reeh, N., Thomsen, H. H., Higgins, A. K., and Weidick, A.: Sea ice and the stability of north and northeast Greenland floating glaciers, Ann. Glaciol., 33, 474-480, 2001.

Rhein, M., Fischer, J., Smethie, W., Smythe-Wright, D., Weiss, R., Mertens, C., Min, D.-H., Fleischmann, U., and Putzka, A.: Labrador Sea Water: Pathways, CFC inventory, and formation rates, J. Phys. Oceanogr., 32, 648-665, 2002.
Rignot, E. and Kanagaratnam, P.: Changes in the Velocity Structure of the Greenland Ice Sheet, Science, 311, 986-990, 2006.

Rigor, I. G., Wallace, J. M., and Colony, R. L.: Response of Sea Ice to the Arctic Oscillation, J. Clim., 15, 2648-2663, 2002.

Ruddiman, W. F.: Late Quaternary deposition of ice rafted sand in the subpolar North Atlantic (lat $40^{\circ}$ to $65^{\circ} \mathrm{N}$ ), Geol. Soc. Am. Bull., 88, 1813-1827, 1977.

Sarafanov, A.: On the effect of the North Atlantic Oscillation on temperature and salinity of the subpolar North Atlantic intermediate and deep waters, ICES Journal of Marine Science: Journal du Conseil, 66, 1448-1454, 2009.

Schmitz, W. J. and McCartney, M.: On the North Atlantic Circulation, Rev. Geophys., 31, 29-49, 1993.

Sejrup, H. P., Lehman, S. J., Haflidason, H., Noone, D., Muscheler, R., Berstad, I. M., and Andrews, J. T.: Response of Norwegian Sea temperature to solar forcing since 1000 A.D, J. Geophys. Res., 115, C12034, doi:10.1029/2010jc006264, 2010.

Shabbar, A., Huang, J., and Higuchi, K.: The relationship between the wintertime North Atlantic Oscillation and blocking episodes in the North Atlantic, Int. J. Climatol., 21, 355-369, 2001.

Sicre, M.-A., Jacob, J., Ezat, U., Rousse, S., Kissel, C., Yiou, P., Eiríksson, J., Knudsen, K. L., Jansen, E., and Turon, J.-L.: Decadal variability of sea surface temperatures off North Iceland over the last 2000 years, Earth Planet. Sc. Lett., 268, 137-142, 2008.

Sicre, M. A., Weckström, K., Seidenkrantz, M. S., Kuijpers, A., Benetti, M., Masse, G., Ezat, U., Schmidt, S., Bouloubassi, I., Olsen, J., Khodri, M., and Mignot, J.: Labrador current variability over the last 2000 years, Earth Planet. Sci. Lett., 400, 26-32, 2014.

Sigl, M., Winstrup, M., McConnell, J. R., Welten, K. C., Plunkett, G., Ludlow, F., Buntgen, U., Caffee, M., Chellman, N., Dahl-Jensen, D., Fischer, H., Kipfstuhl, S., Kostick, C., Maselli, O. J., Mekhaldi, F., Mulvaney, R., Muscheler, R., Pasteris, D. R., Pilcher, J. R., Salzer, M., Schupbach, S., Steffensen, J. P., Vinther, B. M., and Woodruff, T. E.: Timing and climate forcing of volcanic eruptions for the past 2,500 years, Nature, 523, 543-549, 2015.

Steinhilber, F., Beer, J., and Fröhlich, C.: Total solar irradiance during the Holocene, Geophys. Res. Lett., 36, L19704, doi:19710.11029/12009GL040142, 2009.

Straneo, F., Heimbach, P., Sergienko, O., Hamilton, G., Catania, G., Griffies, S., Hallberg, R., Jenkins, A., Joughin, I., Motyka, R., Pfeffer, W. T., Price, S. F., Rignot, E., Scambos, T., Truffer, M., and Vieli, A.: Challenges to Understanding the Dynamic Response of Greenland's Marine Terminating Glaciers to Oceanic and Atmospheric Forcing, B. Am. Meteorol. Soc., 94, 1131-1144, 2013.

Stuiver, M. and Reimer, P. J.: Extended $14 \mathrm{C}$ data base and revised CALIB 3.0 14 C age calibration program, Radiocarbon, 35, 215230, 1993.

Talley, L. D.: Shallow, intermediate, and deep overturning components of the global heat budget, J. Phys. Oceanogr., 33, 530-560, 2003.

Thornalley, D. J. R., Elderfield, H., and McCave, I. N.: Holocene oscillations in temperature and salinity of the surface subpolar North Atlantic, Nature, 457, 711-714, 2009.

Wanner, H., Solomina, O., Grosjean, M., Ritz, S. P., and Jetel, M.: Structure and origin of Holocene cold events, Quaternary Sci. Rev., 30, 3109-3123, 2011. 
Wanner, H., Mercolli, L., Grosjean, M., and Ritz, S. P.: Holocene climate variability and change; a data-based review, J. Geol. Soc., 172, 254-263, 2015.

Yang, Q., Dixon, T. H., Myers, P. G., Bonin, J., Chambers, D., and van den Broeke, M. R.: Recent increases in Arctic freshwater flux affects Labrador Sea convection and Atlantic overturning circulation, Nat. Commun., 7, 10525, doi:10.1038/ncomms10525, 2016.
Zweng, M. M., Reagan, J. R., Antonov, J. I., Locarnini, R. A., Mishonov, A. V., Boyer, T. P., Garcia, H. E., Baranova, O. K., Johnson, D. R., Seidov, D., and Biddle, M. M.: World Ocean Atlas 2013, Volume 2: Salinity, edited by: Levitus, S., A. Mishonov Technical Ed.; NOAA Atlas NESDIS 74, 39 pp., 2013. 